\title{
Dielectric Barrier Discharge Induced By Permanent Magnet In Attraction And Repulsion Conditions For Ozone Generator
}

\author{
Ivan Saputra \\ Department of Electrical Engineering \\ University of Riau \\ Pekanbaru-Riau, Indonesia
}

\author{
Fri Murdiya* \\ Department of Electrical Engineering \\ University of Riau \\ Pekanbaru-Riau, Indonesia
}

*corresponding author: Fri Murdiya, frimurdiya@eng.unri.ac.id

\begin{abstract}
Ozone is used in various area including medicine, drinking water treatment and waste treatment. Ozone can be produced using dielectric barrier discharge which is supplied by high voltage. High voltage occurs in the dielectric barrier discharge such as air gap that it is as a result of the failure of air in maintaining its insulator properties. Power supply used in this study is a parallel resonant push-pull inverter using a fly back transformer. In order to produce good plasma in producing ozone, a magnetic filed is added to dielectric barrier discharge. In this study, a magnet was placed on each anode and cathode electrode with the condition of attraction (model I) and repulsion (model II). The addition of two magnets to each electrode was also carried out under the conditions of attraction (model III) and repulsion (model IV). It is shown that the plasma intensity in the model I and III was higher than model II and IV. The discharge current in the model I and III was higher than model II and IV. The highest ozone concentration was model III and the lowest ozone concentration was in model IV. Model I had a higher ozone concentration than model II.
\end{abstract}

Keywords- ozone, dielectric barrier discharge, plasma, magnetic field, current, voltage.

\section{INTRODUCTION}

Utilization of ozone has been carried out since the 19th century, namely for disinfecting drinking water treatment. Other uses of ozone include medicine, water treatment for refrigeration, pulp and paper and wastewater treatment. In drinking water treatment with ozone has several advantages as a disinfectant substitute for chlorine or chlorine compounds in general. The advantage of ozone is that it does not cause odor, this is different from chlorine compounds which cause a sharp odor. So, the use of ozone is better and ozone can make water fresher [1]

There are several ways to produce ozone, one of which is by using the dielectric barrier discharge method which is supplied with high voltage or also called a high voltage plasma generator. High voltage plasma generators are widely used in areas such as the medical, chemical and physical world. This technology consists of high voltage generators, electrodes and dielectric parts. The way it works is to dielectric barrier discharge with a high voltage which at a certain value will produce plasma that is visible to the eye.
This plasma occurs because of the failure of a material to maintain its insulating properties [2],[3].

Efforts that can be made to increase ozone production can be achieved in two ways, first by optimizing discharge equipment and second by adding combining discharge equipment with catalysts, photo catalysts, or by adding additional fields such as ultrasound and magnetic fields [4].

However, until now to solve the problem in dielectric barrier discharge is still using conventional methods by utilizing electric fields to produce high voltage plasma and using high voltage impulses for its power supply [5]. Therefore, many researchers began to conduct research using magnets.

Fri Murdiya et al. conducted a study in 2018, in their research testing dielectric barrier discharge with a magnetic field. This study examines the effect of the magnetic position induced in the gap of dielectric barrier discharge. This study uses a conventional power supply with a voltage level of 8 $\mathrm{kV}$ and a frequency of $25 \mathrm{kHz}$. The results of this study found that the discharge current at the position of magnet attraction and repulsion is greater than without magnetism and the concentration of ozone under conditions of attraction is greater than the condition of repulsion [3].

Research conducted by Stanislav Pek'arek in 2018 studied the effects of a combination of pulse or sinusoidal control voltages and magnetic fields on current characteristics and ozone production from dielectric barrier discharges injected with air. His research was seen in two pulse polarities, namely positive and negative polarity with a frequency of $10 \mathrm{kHz}$. The results showed that the concentration of ozone produced by sinusoidal voltage was greater than the voltage voltage of the negative voltage. The ozone concentration of the negative polar pulse voltage is greater than the positive polar pulse voltage. Ozone production for negative pulse voltage is equal to sinusoidal voltage, for positive pulse voltage is lower. Magnetic fields slightly increase ozone concentration and ozone production only for discharge with a positive pulse voltage. For sinusoidal stresses or with negative pulses the magnetic field has only a small effect on the concentration of ozone produced by discharge [4]. 
Research conducted by Liu et al in 2016 was to experimentally investigate the impact of parallel magnetic fields on dielectric barrier discharges with a supply voltage of repeating nano second pulses. This experiment was measured using optical measuring devices and electric measuring instruments. The pulse voltage used is $35 \mathrm{KV}$ with a frequency of about $1200 \mathrm{~Hz}, 1000 \mathrm{~Hz}, 600 \mathrm{~Hz}, 300$ $\mathrm{Hz}$ and $100 \mathrm{~Hz}$. The air gap in this study is the distance of $3 \mathrm{~mm}$ and $6 \mathrm{~mm}$, the micro discharge channel is generated and the photocurrent intensity of the plasma is increased by magnetic fields. Micro discharge channels develop along magnetic field lines and the blending emissions from discharges are stronger in dielectric barrier discharges with magnets [5].

Based on previous research, this research was carried out by using magnets to produce high voltage plasma which is good in producing ozone. This research regulates the position of the magnet used is the condition of attraction and repulsion. This research also carried out the addition of magnets from the amount of a magnet on each electrode.

In practice, the thickness of the air gap between the solid insulation material and an anode electrode is relatively smaller than that of the solid insulation. The equation used to calculate the electric field strength of the layered insulation material is determined by the following equation [6].

$$
\begin{aligned}
\mathrm{E} & =\frac{\mathrm{V}}{\varepsilon_{\mathrm{n}}\left(\frac{\mathrm{s}_{1}}{\varepsilon_{1}}+\frac{\mathrm{s}_{2}}{\varepsilon_{2}} \cdots+\frac{\mathrm{s}_{\mathrm{n}}}{\varepsilon_{\mathrm{n}}}\right)} \\
\mathrm{V} & =\text { high voltage }(\mathrm{V}) \\
\varepsilon_{n} & =\text { n-Permitivity } \\
s_{n} & =\text { the thickness of solid insulator }(\mathrm{cm})
\end{aligned}
$$

Silent plasma discharge is a discharge that can be operated at atmospheric pressure. This large-scale plasma discharge is widely used by companies to produce ozone with the source gas used is free air and oxygen. The main characteristic of dielectric barrier discharge is its narrow discharge gap with a millimeter spacing of one of the electrodes covered with an insulating layer [7].

Barrier discharge dielectric is two parallel plates flanking the insulating material which is also called dielectric. Therefore, the configuration of the dielectric barrier discharge is similar to an electrical component called a capacitor. Therefore the equivalent circuit of the dielectric barrier discharged can be represented as a load capacitor. However, the insulation material contained in the dielectric barrier discharge has two types of dielectric material, namely air and solid insulation materials. So there are two capacitance found in DBD which is denoted by $\mathrm{Cg}$ and $\mathrm{Cd}$. Capacitance configuration of the dielectric barrier discharge is shown in figure 1 below [8].
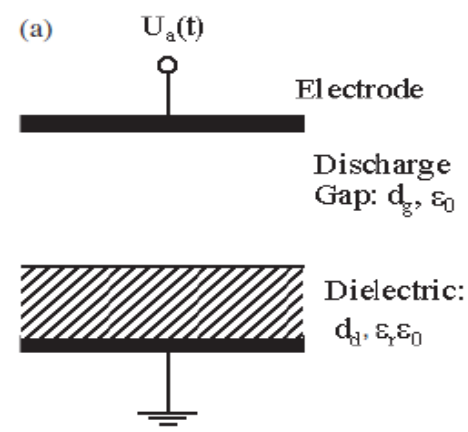

Figure 1. Capacitance of Dielectric Barrier Discharge

The dielectric capacitance $(\mathrm{Cd})$ and the gap capacitance $(\mathrm{Cg})$ can be calculated by the formula below.

$$
\mathrm{C}_{\mathrm{d}}=\varepsilon_{0} \varepsilon_{\mathrm{r}} \frac{\mathrm{A}}{\mathrm{d}_{\mathrm{d}}}, \mathrm{C}_{\mathrm{g}}=\varepsilon_{0} \frac{\mathrm{A}}{\mathrm{d}_{\mathrm{g}}}
$$

$$
\begin{aligned}
d_{d} & =\text { Dielectric thickness }(\mathrm{cm}) \\
d_{g} & =\text { Air gap distance }(\mathrm{cm}) \\
A & =\text { Discharge area }\left(\mathrm{cm}^{2}\right) \\
\varepsilon_{0} & =\text { vacuum permittivity } \\
\varepsilon_{r} & =\text { dielectric constant }
\end{aligned}
$$

So that the total dialectic barrier discharge capacitance is obtained using the formula below.

$$
\mathrm{C}_{\mathrm{DBD}}=\frac{1}{\left(1+\frac{\mathrm{C}_{\mathrm{g}}}{\mathrm{C}_{\mathrm{d}}}\right)}
$$

Naturally, through ultraviolet radiation sunlight occurs the formation of ozone. Ozone can absorb UV rays between $240 \mathrm{~nm}-320 \mathrm{~nm}$. Chapman explained that ultraviolet radiation can break down oxygen gas in free air to break down into two oxygen atoms. This process is called photolysis and is shown in figure 2 below. This oxygen atom will naturally collide with oxygen gas molecules that are around it to form new molecules called ozone. The reverse event can occur in ozone if sunlight is absorbed by ozone with a wavelength of 240-340nm and causes ozone to decompose back into oxygen and one oxygen atom [9]. This process is shown in the chemical reaction below and in figure 2 :

$$
\begin{aligned}
& \mathrm{O}_{2}+h v \rightarrow 0+0 \\
& \mathrm{O}_{2}+\mathrm{O}+\mathrm{M} \rightarrow \mathrm{O}_{3}+\mathrm{M} \\
& \text { where } \mathrm{M} \text { is } \mathrm{O}_{2} \text { or } \mathrm{N}_{2} \text { ) } \\
& \mathrm{O}_{2}+h v \rightarrow \mathrm{O}_{2}+0 \\
& \mathrm{O}_{3}+\mathrm{O} \rightarrow \mathrm{O}_{2}+0
\end{aligned}
$$




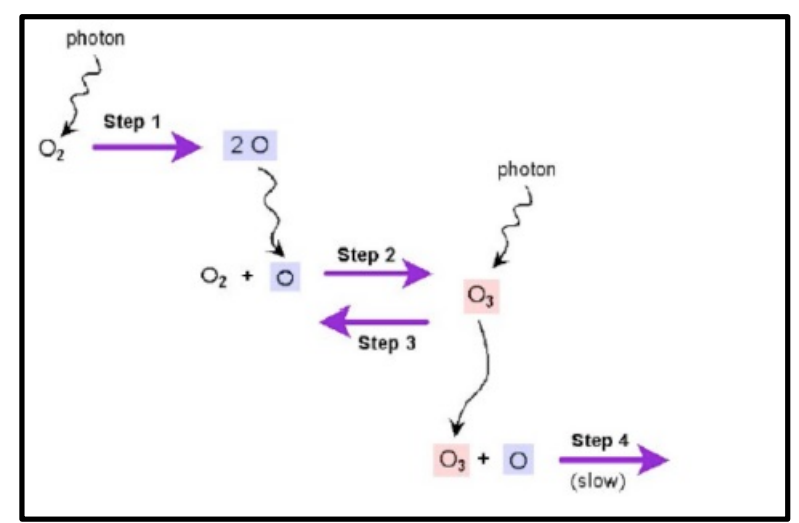

Figure 2. Ozone Formation and Decomposition

Magnetic induction is closely related to the Maxwel equation which is usually called the induction law shown in the equation below. The induced magnetic field is B with a Tesla unit [10]. The formula below explain about the correlation of $\mathrm{E}$ and $\mathrm{B}$.

$$
\oint_{\mathrm{K}} E \cdot d s=-\oint_{\mathrm{S}} B \cdot d l
$$

The radial effect of magnets on the ozone production discharge chamber is related to the Lorentz force oriented to the axis [4]. The total force is

$$
\mathrm{f}_{\text {total }}=\mathrm{F}_{\mathrm{e}} \mathrm{n}+\mathrm{F}_{\mathrm{m}} \mathrm{n}=\mathrm{qnE}+\mathrm{j} \times \mathrm{B}
$$

where:

$$
\begin{aligned}
& E=\text { electric field }(\mathrm{kV} / \mathrm{cm}) \\
& n=\text { plasma density } \\
& j=\text { current density }\left(A / \mathrm{m}^{2}\right) \\
& B=\text { magnetic field (Tesla) }
\end{aligned}
$$

Lorentz's force works on micro discharge discharge, this will affect the direction, interaction between discharge and its possible dimensions. Lorentz's force can also cause visual changes in discharge.

\section{Research Methodology}

The method used in this research was to design a high voltage inverter power supply and dielectric barrier discharge. After that, it continued to make power supply devices and dielectric barrier discharge. Tools that have been built would then be tested so as to produce plasma in the air gap. At the dielectric barrier discharge, measurements of current, voltage, plasma shape and ozone concentration were measured.

The power supply that would be built was the power supply as a source voltage rectifier, the IC4040 switch control circuit, push pull inverter circuit and parallel LC resonant circuit and fly back transformer as a voltage converter to high voltage. The circuit was placed in a panel that has an on / off button in the form of a push button. While dielectric barrier discharge was composed of anode and cathode electrodes, the ceramic dielectric, and speaker permanent magnet.
The testing process was carried out by adjusting the distance of the dielectric barrier discharge at a distance of $1 \mathrm{~mm}$ and $2 \mathrm{~mm}$. This test was also done by adjusting the speaker permanent magnet that was above the anode electrode and under the cathode electrode with four magnetic conditions.

The power supply used in this study was a parallel resonant push pull inverter circuit that was controlled by IC CD4047 with a SMPS supply that serves to rectify the $220 \mathrm{~V}$ source voltage. The SMPS output voltage was 11 VDC then used to supply the CD4047 IC control circuit. The CD4047 IC output of 9.10 VDC was then connected to the gate of the mosfet with an oscillation frequency of $20 \mathrm{kHz}$. In order to get an output of $10.49 \mathrm{~V}$ the inverter would be supplied to the Fly back transformer with the fly back primary winding had a center tap connected from the 11 VDC SMPS output through the $100 \mathrm{mH}$ inductor. The power supply circuit could be seen more clearly from figure 3 below.

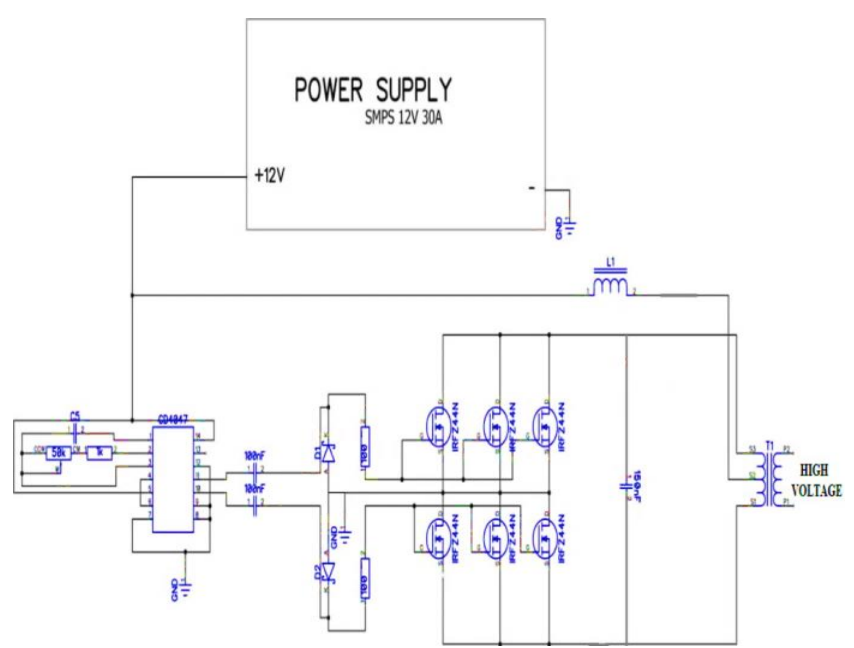

Figure 3. High voltage electronics circuit

Dielectric barrier discharge is a load that will be supplied with a push pull inverter power supply. In this dielectric barrier discharge the ionization process will occur due to the electric discharge in the form of plasma which functions as a catalyst of Ozone. Dielectric barrier discharge (DBD) has a construction similar to a capacitor, which is two plates separated by a dielectric material. Figure 4 . below shows the construction of DBD.

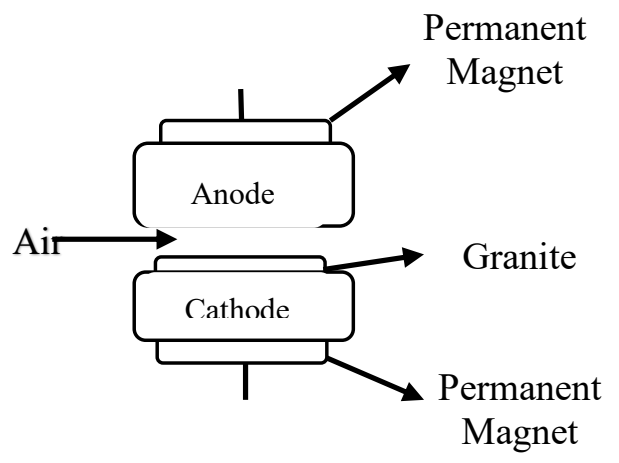

Figure 4. Dielectric Barrier Discharge Construction 
In this study, iron plates were used as cathode and anode electrodes. This plate is a circle that has a diameter of $10 \mathrm{~cm}$, this plate is attached to the mica frame. Between the two plates there are dielectrics which separate them, there are two types of dielectrics namely air dielectric and solid dielectric. Air dielectric is also called gap, and the solid dielectric used is ceramic material with a thickness of $9 \mathrm{~mm}$.

Permanent magnets used are speaker magnets, these magnets are placed above the positive electrode and below the negative electrode. Magnets are set in conditions of attraction and repulsion. Measurements to be carried out in this study are measurements of DBD current, DBD voltage, plasma form and Ozone Concentration. The test scheme can be seen in figure 5. below.

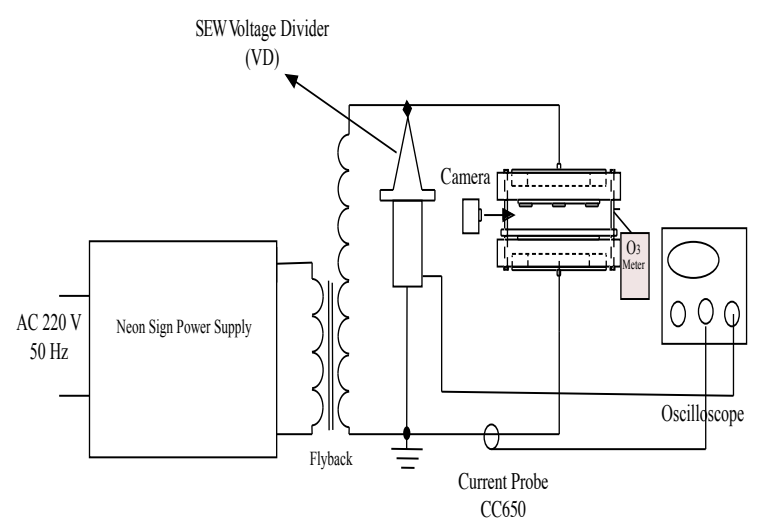

Figure 5. Scheme of measurement of DBD
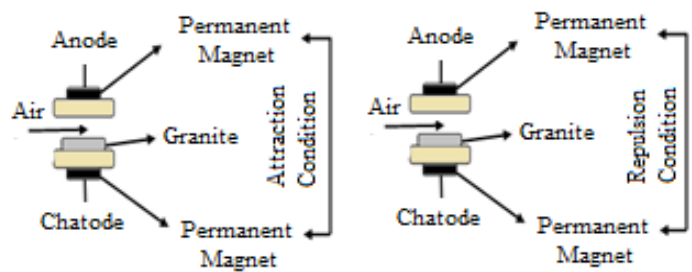

a

b
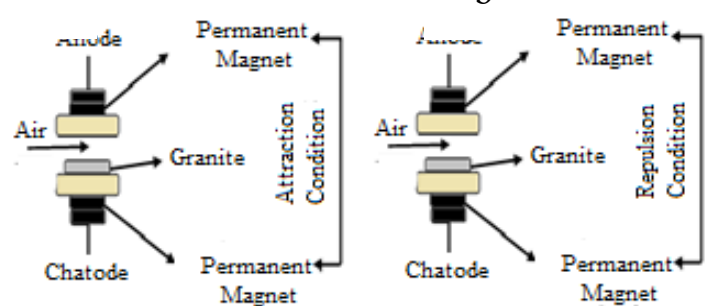

c

d

Figure 6. Dielectric Barrier Discharge with (a) Model I, (b) Model II, (c) Model III, (d) Model IV

This measurement was carried out on 4 (four) models of magnetic conditions which can be seen in figure 6 below. These four models of magnetic conditions are:

1. Model I is the condition of attraction with one magnet on each electrode

2. Model II, namely the repulsion condition with one magnet on each electrode
3. Model III is the condition of attraction of two magnets in each electrode

4. Model IV, namely the repulsion of two magnets in each electrode

\section{DATA ANALYSIS AND Discussion}

\section{A. Plasma Light Intensity}

The plasma form is seen using a mobile camera using the A spectra Mini android application. A spectra Mini is spectrometer that functions to see the spectrum of light from an image. This aspect shows the value of light intensity. If the value is higher then the luminance or brightness of the light is higher.

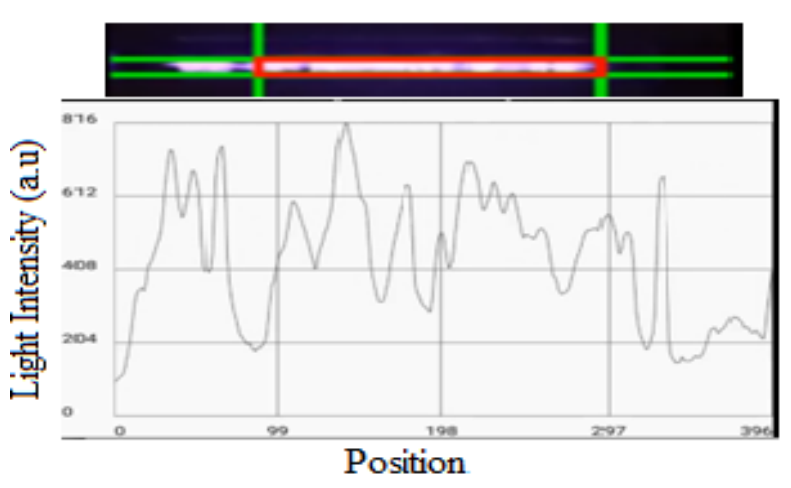

(a)

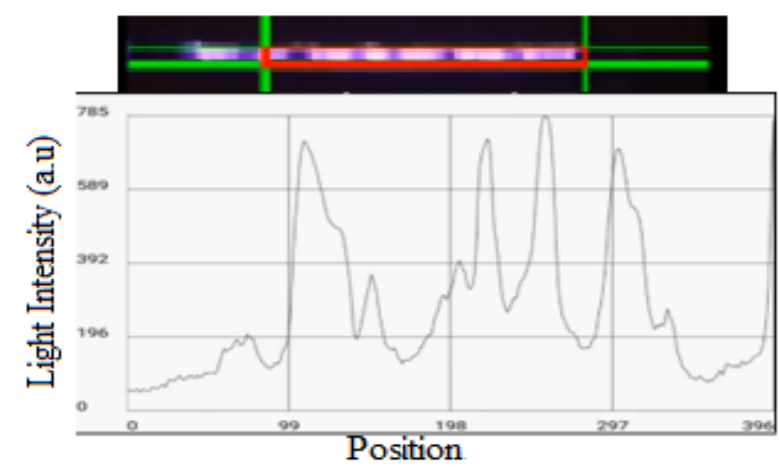

(b)

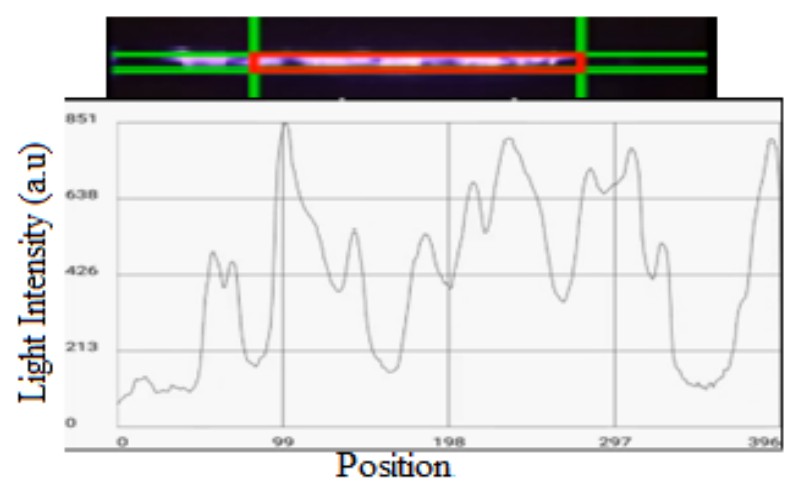

(c) 


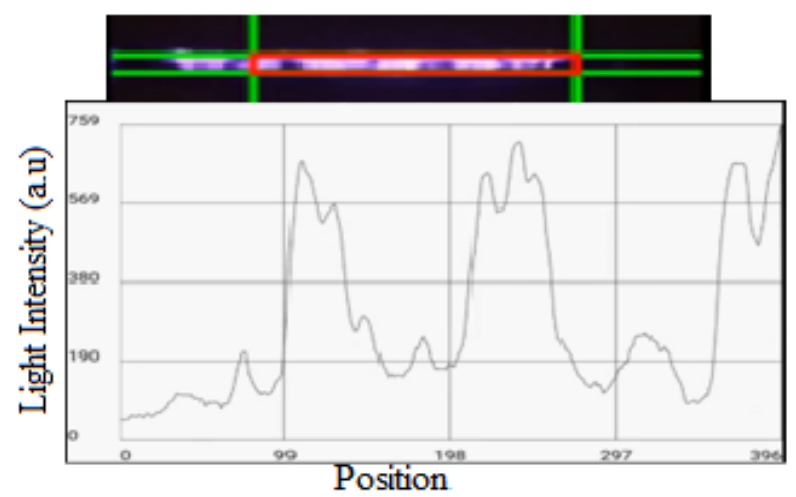

(d)

Figure 7. Plasma intensity of DBD for (a) model I, (b) model II, (c) model III, (d) model IV

In figure 7 above shows the plasma test at a distance of 2 $\mathrm{mm}$ and obtained the highest light intensity in model III. The lowest light intensity in model IV. In model I it has a higher light intensity than model II.

\section{B. Discharge Current and DBD Voltage}
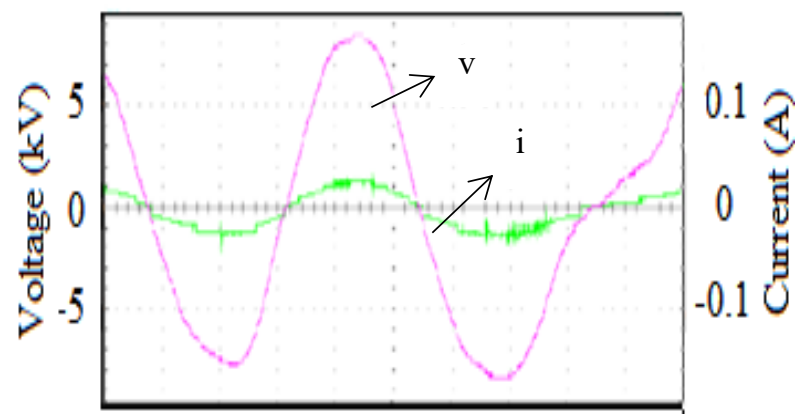

(a)

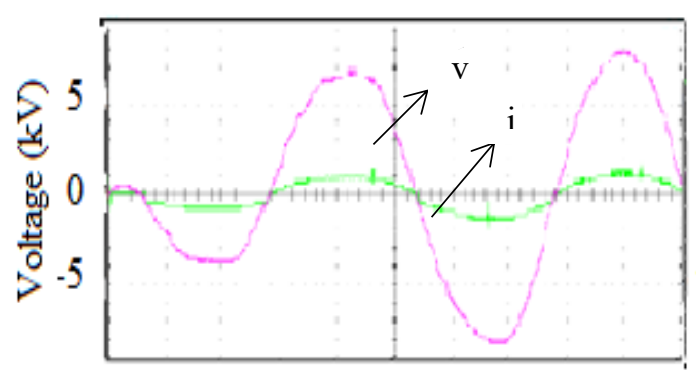

0.1 导
0 憘
-0.1 塄

(b)

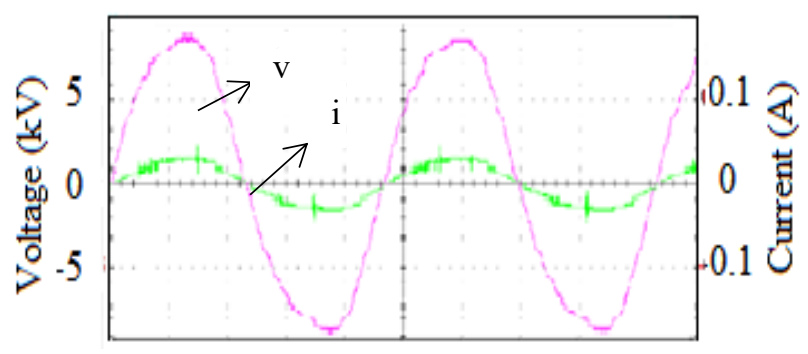

(c)

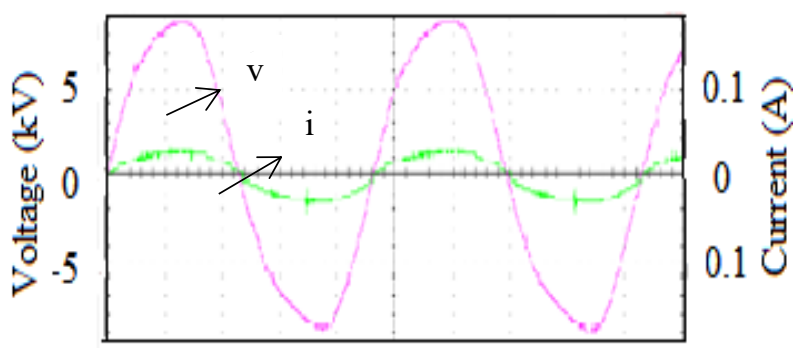

(d)

Figure 8. Voltage and current of DBD for (a) model I, (b) model II, (c) model III, (d) model IV

From figure 7, it can be seen that the highest dielectric barrier discharge current at an air gap of $2 \mathrm{~mm}$ is in the attraction condition between permanent magnets (Model III). Thus the value of the current under the attraction condition at a distance of $2 \mathrm{~mm}$ is higher than repulsion condition.

\section{Ozone Production}

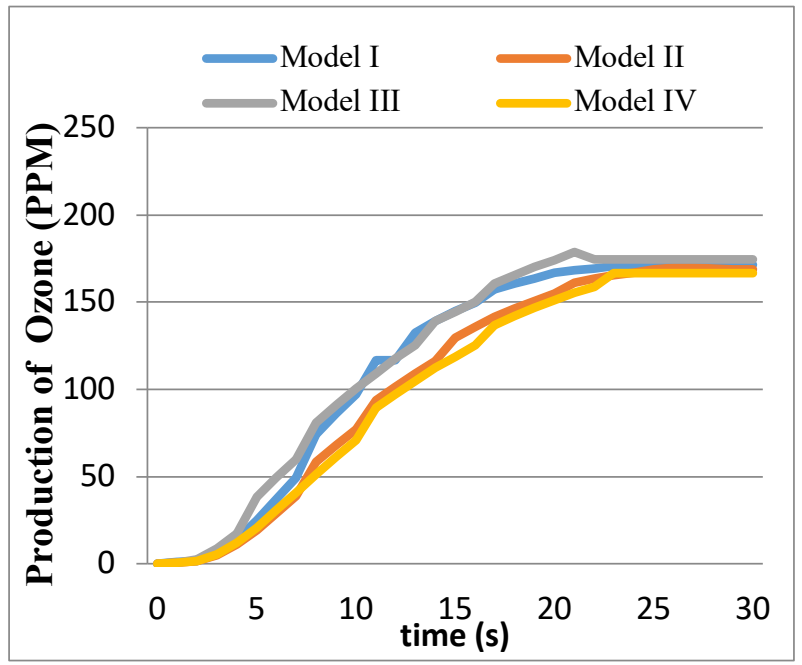

Figure 9. Ozone Production for all models

Figure 9 shows a graph of measurements of ozone concentration over time in all models. For model III produces high ozone concentrations of all models. The DBD condition for Model I is higher than Model II. The lowest ozone concentration under repulsion conditions in model IV.

\section{CONCLUSION}

Based on the results of tests and analyzes that have been made, several conclusions are obtained such as the even distribution of plasma in the dielectric barrier discharge (DBD) at an air gap of $2 \mathrm{~mm}$ in all magnetic conditions. The intensity of plasma models I (the conditions of attraction of one magnet up and down) and model III (conditions of attraction of two magnets up and down) are higher than the model II (conditions of repulsion between one magnet up 
and down) and IV (repulsion condition between the two magnets up and down). Furthermore, DBD current flows from all models produced showed the highest value in model III. The highest ozone concentration is in model III of all test models. The ozone concentration of model I is higher than model II. Model IV has the lowest ozone concentration of all models.

\section{ACKNOWLEDGMENT}

We thanks to Lembaga Penelitian dan Pengabdian Kepada Masyarakat Universitas Riau (LPPM UNRI) for financial support through Penelitian Percepatan Inovasi in 2019, with the number of contract: 1026/UN.19.5.1.3/PT.01.03/2019.

\section{REFERENCES}

[1] Prihatinningtyas, E, "Ozon Suatu Dilema, Warta Limnologi", No. 40, Oktober 2006.

[2] Murdiya, F., Suwitno, Anto, B., Ervianto, E., Hamdani, E., \& Amri, A. "Barrier Discharge In Magnetic Field: The Effect Of Magnet Position Induced Discharge In Gap". 2nd International Conference on Electrical Engineering and Informatics (Icon EEI 2018), BatamIndonesia, 2018.
[3] Murdiya, Febrizal, Amun Amri, "The performance of surface barrier discharge in magnetic field driven by half bridge series resonance converter", Journal of Mechatronics, Electrical Power, and Vehicular Technology, Vol.8, No.2, pp.95-102, 2017.

[4] Peka'rek, S, "Experimental Study of Pulse Polarity and Magnetic Field on Ozone Production of the Dielectric barrier dischargein Air", Plasma Chemistry Plasma Processing, Springer, 2018

[5] Liu, Y., Qi, H., Fan, Z., \& Ren, C. S, "The impacts of magnetic field on repetitive nanosecond pulsed dielectric barrier dischargein air", Physic of Plasmas, vol. 23, 2016.

[6] Tobing, B. L, "Pengujian Tegangan Tinggi", Gramedia Pustaka Utama, 2003.

[7] Nur, M, "Fisika Plasma dan Aplikasinya", Semarang, Universitas, 2011.

[8] Shuhai Liu, Manfred Neiger, "Electrical modelling of homogeneous dielectric barrier discharges under an arbitrary excitation voltage", Journal of Physics D: Applied Physics, vol. 36, Number 24, IOP Publishing Ltd, 2003.

[9] Novia dan Syafarudin, A, "Produksi Ozon Dengan Bahan Baku Oksigen Menggunakan Alat Ozon Generator", Jurusan Teknik Kimia, Universitas Sriwijaya, 2013.

[10] Gerthsen, C. Kneser. Vogel, "Fisika Listrik Magnet dan Optik", Diterjemahkan oleh: Musaddiq Musbach, Jakarta, 1996., BatamIndonesia, 2018 